\title{
EL IMPACTO DEL TURISMO DE MASAS EN LAS ISLAS CANARIAS EN EL CONTEXTO DE LAS RESERVAS MUNDIALES DE LA BIOSFERA
}

\author{
José Ángel Hernández Luis \\ Alejandro González Morales \\ Santiago Hernández Torres \\ Antonio Ángel Ramón Ojeda \\ Universidad de Las Palmas de Gran Canaria
}

\section{RESUMEN}

Canarias es uno de los destinos turísticos principales de Europa. El Archipiélago recibió en 2015 más de 14 millones de turistas y todo ello en un territorio muy limitado $(7.4$ mil km² y una población de 2.1 millones). Las dimensiones de estas cifras adquieren relevancia en un contexto donde el $63 \%$ de la superficie de las Islas ha sido declarada Reserva Mundial de la Biosfera. Se estudia aquí pues, el impacto del turismo -así como algunas alternativas en aras de paliar dicho impacto-, en las cinco islas que han sido declaradas en su integridad como tales, partiendo de sus particularidades.

Palabras clave: Islas Canarias; Reserva Mundial de la Biosfera; turismo de masas; Planes Insulares de Ordenación; impactos del turismo.

\section{The impact of mass tourism in the Canary Islands in the context of World Biosphere Reserves}

\section{ABSTRACT}

The Canary Islands is a major tourist destination in Europe. The Archipelago received than 14 million tourists in 2015, and in a very limited territory (only 7.4 thousand $\mathrm{km}^{2}$ and

Recibido: 10 de marzo de 2016

Devuelto para su revisión: 5 de septiembre de 2016

Aceptado: 30 de octubre de 2016

Departamento de Geografía. Universidad de Las Palmas de Gran Canaria. C/Pérez del Toro, 1. 35003 LAS PALMAS DE GRAN CANARIA (España). E-mail: jose.hernandez@ulpgc.es, alejandro.gonzalez@ulpgc.es, santiago.hernandeztorres@ulpgc.es, toni.ramon@ulpgc.es 
a population of 2.1 million). These figures become relevant in a context where $63 \%$ of the area of the islands has been declared a World Biosphere Reserve. We study the impact of tourism -as some alternatives in order to reduce this impact-on the five islands that have been declared in full as World Biosphere Reserves, based on their characteristics.

Key words: Canary Islands; World Biosphere Reserve; mass tourism; island plans; impacts of tourism.

\section{INTRODUCCIÓN}

La localización del Archipiélago canario, próximo a la latitud subtropical en el Océano Atlántico, además de su distancia con respecto a los principales focos emisores del turismo de la Europa Occidental -a cuatro o cinco horas en transporte aéreo como máximo-, ha convertido a las Islas en un territorio muy demandado por los turistas, especialmente después del advenimiento de la moda del turismo de sol y playa en los años sesenta.

Las cifras son más que elocuentes, pues en un territorio que ni siquiera alcanza los 7.5 mil km² y una población de 2.1 millones, las Islas casi recibieron en 2015 unos 12 millones de turistas extranjeros, a lo que hay que añadirle aproximadamente dos millones procedentes del resto del Estado español.

Todo ello en un contexto donde Canarias destaca por su alto número de espacios naturales con alguna figura de protección, en concreto 146, que representan un $40 \%$ de su territorio. Además, cinco de las siete islas, han sido declaradas en su "integridad" por la UNESCO como Reserva Mundial de la Biosfera, a saber: Lanzarote (en 1993); El Hierro (en 2000); La Palma (en 2002); Fuerteventura (en 2009) y La Gomera (en 2012)1. Son pues en estas cinco islas donde basamos nuestro estudio, partiendo de la base de que se trata de territorios donde el grado de protección es muy alto y donde algunos de ellos, sobre todo las islas de Lanzarote y de Fuerteventura, sufren una presión turística muy elevada, evaluándose aquí el impacto que dicha actividad ha podido causar en cada uno de estos territorios. No obstante, hay que argumentar que cada conjunto insular constituye un marco diferenciado con respecto a los restantes, no solamente por la presión turística -que es bastante diversa entre las islas de este estudio-, sino también por la variedad de su sistema ambiental, pues en unas islas predominan los valores geomorfológicos, como por ejemplo en Lanzarote o Fuerteventura, mientras que en otras destaca su biodiversidad, como es el caso de La Gomera.

Pues bien, podemos decir que las sucesivas declaraciones de Reservas Mundiales de la Biosfera de las citadas islas en su integridad, deriva del inexcusable valor y singularidades paisajísticas, ambientales y climáticas. Ello ha supuesto una oportunidad altamente positiva de cara a salvaguardar el patrimonio natural de un valioso territorio, escaso y frágil, a la vez que posibilitar una marca turística diferenciada de cada conjunto insular.

1 También un $42 \%$ de la superficie de la isla de Gran Canaria (mitad occidental) y un $8 \%$ de Tenerife (Macizo de Anaga), fueron declarados en 2005 y 2015 respectivamente, Reservas Mundiales de la Biosfera, si bien no se consideran aquí, pues como decimos no fueron declaradas en su integridad y, además, la mayor presión turística de estas Islas se encuentra fuera de estas áreas. 
Sin embargo, el desarrollo turístico desmesurado de estos últimos años, parece constituir uno de los puntos de ruptura del actual equilibrio territorial que repercute de forma negativa en la calidad medioambiental de estas islas y que, particularmente en este trabajo, demostramos a través de diversos indicadores. Pero es precisamente esta dicotomía entre una parte de los territorios insulares, donde predominan espacios naturales de alto valor, frente a otros que presentan un fuerte desarrollo urbano y humano, donde reside el interés por evaluar cómo se relaciona la conservación del patrimonio territorial con el desarrollo económico, fundamentalmente el turístico.

En suma, en el artículo desarrollamos en primer lugar un marco territorial a modo de presentación, donde además hacemos hincapié en las actuales Reservas Mundiales de la Biosfera de Canarias. Todo ello se relaciona con el incremento demográfico y de la actividad económica - particularmente derivado del turismo-, para posteriormente analizar el impacto que esta actividad ha tenido en el territorio. Todo ello nos da pie para investigar cómo el actual planeamiento, las normativas y las diferentes iniciativas, han podido favorecer -o no-, el desarrollo sostenible del territorio y, con ello, la preservación del título de Reserva Mundial de la Biosfera para los diferentes conjuntos insulares.

\subsection{Marco conceptual y metodológico}

El interés por el estudio de los impactos en las Reservas Mundiales de la Biosfera podemos calificarlo como multifacético, tanto por la diversidad de puntos de vista tratados (impactos sobre la vegetación, sobre el suelo, sobre la fauna, sobre la economía, etc.), como por la procedencia curricular de los estudiosos del tema. Lo cierto es que, en los últimos años, ha aumentado el interés por estos territorios, ya sea por la creciente afección hacia ellos, como también por la mayor sensibilidad de la comunidad científica y, evidentemente, el incremento de estos espacios en los cinco continentes.

Así pues, la literatura sobre el particular es muy diversa, como es el caso de la que aborda los impactos económicos y sociales en estos espacios (Zube y Busch, 1990; Montoya Ayala, 2004; Ellis y Porter-Bolland, 2008; Rescia, 2010), algunos con particular énfasis en el desarrollo local (Zube y Busch, 1990; Li, 2006; Văidianu, 2014). Del mismo modo, los impactos físicos han sido uno de los temas más recurrentes cuando se abordan estudios relacionados con las Reservas de la Biosfera, tratándose desde muy diversas perspectivas, como por ejemplo impactos sobre la flora, la fauna, el cambio climático, la disminución de los recursos hídricos (Duffy, 2001; Ngana, 2003; Byers, 2007; Ainz Ibarrondo, 2008; kerbiriou, 2008; Chettri, 2010; Ormaetxea, 2010; Huzui, 2012; Sánchez, 2013; Vidal y Rendón-Salinas, 2014). En especial, dadas las características de fragmentación territorial que presentan las islas y los problemas que ello conlleva desde el punto de vista del abastecimiento energético, sobre todo en islas con la condición de Reservas de la Biosfera, han proliferado estudios relacionados con las energías alternativas, en aras de disminuir los impactos que provoca tal actividad de modo tradicional, revalorizando el medio ambiente en estos espacios (Iglesias y Carballo, 2011; Sierra, 2013; Veigas y Iglesias, 2014).

Pero en este trabajo lo que nos interesa es destacar sobre todo el papel del turismo en las Reservas de la Biosfera. Desde este punto de vista, las citadas Reservas han sido un 
buen justificante para impulsar un turismo con características sostenibles, teniendo como baluarte la población que en ellas habita. De este modo, varios autores han destacado la revalorización del paisaje para la creación de senderos y rutas temáticas (Batisse, 1990; Zube y Busch, 1990; Primack, 1998; Duffy, 2001; Ellis y Porter-Bolland, 2008; Esquivel, 2010), pero de modo general otros han optado por analizar, como tema central, el perfil del visitante (Leco Berrocal, 2015); la afección de los turistas sobre los recursos hídricos (Ngana, 2003); el impacto en general del turismo en estas Reservas (Araya, 2007; Esquivel, 2010; Karez, 2012), etc.

De modo muy específico, la fragilidad de los sistemas insulares y su variedad paisajística, ha repercutido en que una buena cantidad de islas hayan sido declaradas como Reservas de la Biosfera, ya sea de modo parcial o integral. A su vez, estos territorios suelen presentar un mayor atractivo turístico, por lo que la confrontación entre conservación y explotación turística suele ser un tema de difícil equilibrio y donde, tal y como hacemos en el presente trabajo, se han centrado muchos autores (Battise, 1990; Kuijper, 2003; González y Hernández, 2005; Baine, 2007; Mow, 2007; Kerbiriou, 2008; Cusick, 2009; Sobral García, 2011; Gourmelon, 2013; Okano y Matsuda, 2013).

Desde el punto de vista metodológico, abordamos en primer lugar un diagnóstico del territorio, apuntando cuáles son las causas del crecimiento del turismo en Canarias, con especial referencia a los espacios Reservas de la Biosfera y los indicadores del impacto del turismo en las Islas que han sido declaradas como tales en su integridad. Del mismo modo, el análisis de las recientes normativas en aras de la consecución de un turismo más sostenible, así como el techo aconsejable de camas turísticas, nos sentarán las bases para establecer una nueva propuesta de gestión sostenible de estos territorios, con el fin de alcanzar los objetivos que exige la UNESCO para la renovación de la mención de Reservas Mundiales de la Biosfera, siguiendo los planteamientos de la sostenibilidad. Esto último es muy importante, en tanto que, especialmente a partir de 2014, la UNESCO ha iniciado el procedimiento conocido como "estrategia de salida”, por el que aquella Reserva que no cumpla con las obligaciones estatutarias adquiridas, se le iniciará un "expediente de descatalogación”, pudiendo cualquier Reserva por tanto -y declarada como tal-, perder tal condición.

\section{BREVE ANÁLISIS DEL MARCO TERRITORIAL}

Las Islas Canarias han aumentado su población en casi un 120 por ciento en los últimos 50 años, hasta llegar a los 2.1 millones de habitantes en 2011 (algo más de 2.3 si se incluye la población turista que entra al Archipiélago). Este hecho, conjuntamente con el trasvase de población activa desde el sector primario al terciario, ha favorecido un cambio espectacular de la socio-economía de las Islas, sobre todo al amparo del desarrollo turístico (Wanhill, 2000; Rubio Gil, 2003; Santana Turégano, 2005, González Lemus, 2012).

En la actualidad, no se puede decir que todo el terciario dependa de la actividad turística, pero sí es cierto que el turismo repercute en otros sectores económicos, como por ejemplo la construcción dentro del secundario y, en general, sobre el resto de la economía canaria (Gobierno de Canarias, 2008; Hernández Martín, 2011). De cualquier manera, la actividad terciaria en Canarias genera en la actualidad un $78 \%$ del Valor Añadido Bruto $\mathrm{y}$, sin duda, ha contribuido al incremento de la renta per capita. 
Figura 1

CARACTERÍSTICAS BÁSICAS

DE LAS RESERVAS DE LA BIOSFERA DE CANARIAS EN 2016

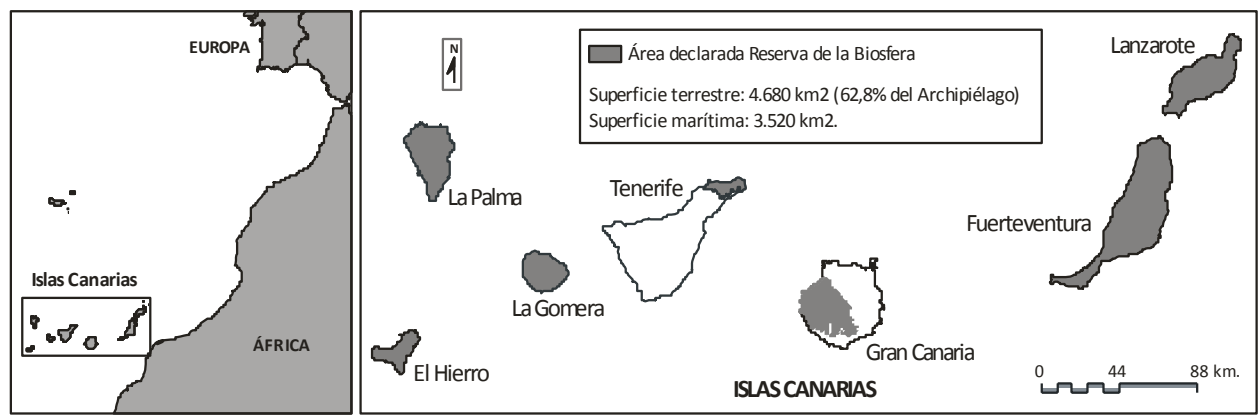

Fuente: GRAFCAN e Instituto Canario de Estadística. Elaboración propia.

\section{Cuadro 1 \\ PRINCIPALES MACROMAGNITUDES \\ DE LAS ISLAS CANARIAS ENTRE 1960 Y 2011}

\begin{tabular}{|c|c|c|c|c|c|}
\hline \multirow[b]{2}{*}{ Años } & \multirow[b]{2}{*}{ Población } & \multirow[b]{2}{*}{$\begin{array}{c}\text { Turistas } \\
\text { extranjeros }\end{array}$} & \multicolumn{3}{|c|}{ Activos ocupados } \\
\hline & & & Sector $1^{\circ}$ & Sector $2^{\circ}$ & Sector $3^{\circ}$ \\
\hline 1960 & 966.177 & 69.000 & 185.025 & 47.798 & 113.010 \\
\hline 1970 & 1.125 .442 & 821.000 & 127.716 & 90.174 & 192.205 \\
\hline 1981 & 1.367 .669 & 2.521 .500 & 87.275 & 93.785 & 276.583 \\
\hline 1991 & 1.493 .784 & 5.495 .000 & 44.133 & 96.753 & 356.168 \\
\hline 2001 & 1.781 .366 & 10.137 .202 & 39.160 & 109.661 & 488.370 \\
\hline 2011 & 2.082 .655 & 10.176 .968 & 21.520 & 89.900 & 657.260 \\
\hline $\begin{array}{l}\text { Variación } \\
1960-2011\end{array}$ & 115,56 & 14.649 .23 & -88.37 & 88.08 & 481.59 \\
\hline
\end{tabular}

Fuente: Instituto Canario de Estadística. Elaboración propia.

De cualquier manera, la distribución de la población y de la riqueza dentro del Archipiélago varía considerablemente. En ello inciden multitud de parámetros: desde causas históricas hasta condicionantes del relieve, desarrollo de las infraestructuras portuarias, etc. Esta desigual distribución tiene consecuencias notables desde el punto de vista del impacto territorial, hecho que se ha profundizado desde la llegada en masa del turismo a las Islas a finales de los años sesenta (Hernández Luis, 2008). Pero las Islas difieren notablemente, tanto desde el punto de vista demográfico como económico, tal y como podemos apreciar en el Cuadro 2, donde las densidades de población son muy importantes, al igual que la entrada de turistas. 


\section{Cuadro 2 \\ PRINCIPALES CARACTERÍSTICAS INSULARES DE LAS ISLAS CANARIAS EN 2015}

\begin{tabular}{|l|c|c|c|c|}
\hline Islas & Población & $\begin{array}{c}\text { Densidad } \\
\left(\mathbf{h a b} / \mathbf{k m}^{\mathbf{2}}\right)\end{array}$ & $\begin{array}{c}\text { Turistas } \\
\text { extranjeros }\end{array}$ & $\begin{array}{c}\text { Valor Añadido } \\
\text { Bruto (\%) }\end{array}$ \\
\hline Gran Canaria & 847.830 & 543 & 3.271 .122 & 42 \\
\hline Tenerife & 888.184 & 437 & 4.203 .928 & 42 \\
\hline Lanzarote & 143.209 & 169 & 2.193 .273 & 5 \\
\hline La Palma & 82.346 & 116 & 125.953 & 4 \\
\hline Fuerteventura & 107.367 & 65 & 1.965 .573 & 6 \\
\hline La Gomera & 20.783 & 56 & ---- & 0.5 \\
\hline El Hierro & 10.587 & 39 & ---- & 0.5 \\
\hline Total & 2.100 .306 & 282 & $11.759 .849 *$ & 100 \\
\hline
\end{tabular}

* Solo se incluyen los turistas extranjeros entrados por vía aérea. En 2015, las llegadas de turistas en cruceros a Canarias se elevó a 2.185.469.

Fuente: Instituto Canario de Estadística. Elaboración propia.

En suma, los desequilibrios entre islas son notables, hecho que incide en impactos bastante diferenciados desde el punto de vista turístico (Simancas Cruz, 2006; González Lemus, 2012). En cualquier caso, hay que comentar que todavía las economías de las islas más occidentales (La Gomera, El Hierro y La Palma), dependen en alto grado de la agricultura de exportación, a diferencia del resto de las islas donde la especialización turística es máxima.

\section{LAS CAUSAS DEL CRECIMIENTO DEL TURISMO EN CANARIAS: EL CASO PARTICULAR DE LAS ISLAS RESERVA MUNDIAL DE LA BIOSFERA}

El modelo turístico que se gesta en Canarias a partir de los años sesenta es consecuencia de un proceso paulatino, en el que se sucedieron una serie de factores tanto externos como internos:

Causas internas: Se podrían denominar como tales las siguientes:

1. Elementos naturales: Los paisajes insulares, en especial la existencia de playas y un excelente clima, han convertido a las Islas en un destino de sol y playa, en especial las islas de Tenerife, Gran Canaria, Lanzarote y Fuerteventura.

2. Situación socioeconómica: Canarias orientó su economía hacia la actividad primaria, especialmente la agricultura. No obstante, en algunas islas como Lanzarote y Fuerteventura, la escasez de agua impidió una agricultura de alta rentabilidad como en las islas más occidentales. Ante ello, la alternativa turística era más que atractiva.

3. Mejora de la accesibilidad: Este aspecto es estratégico para Canarias, por lo que sobre todo las mejoras aeroportuarias, han facilitado el turismo de masas en las Islas.

4. Precios del suelo: La existencia de grandes paquetes de suelo en el litoral de las Islas a disposición del capital privado y a un coste relativamente bajo, favoreció igualmente la conversión a suelo turístico desde fechas tempranas (Gaviria, 1974). 
Causas externas: Los condicionantes externos que van a fomentar los viajes turísticos a nivel mundial y, en particular, a Canarias, serían sobre todo los siguientes:

1. Mejora progresiva de la tecnología del transporte: especialmente del modo aéreo que facilitó una importante caída del precio del transporte y, por ende, favoreció el turismo entre las clases más populares, siendo el preludio del turismo de masas en las Islas.

2. Incremento de la renta per capita; $y$, por ende, de la mejora del nivel de vida, fruto de diversos hechos socioeconómicos (descenso de la natalidad; incorporación de la mujer al mercado laboral, etc.), facilitando la aparición de una potente clase media en disposición para hacer turismo.

3. Debilidad de la antigua moneda española (la peseta): frente a otras como el marco alemán o la libra esterlina, cuestión ésta que favorecía un elemento atrayente para los extranjeros.

4. Tendencia a disfrutar de una jubilación a una edad cada vez más temprana: factor que unido al aumento de la esperanza de vida, facilitó el incremento de los viajes turísticos de los efectivos de mayor edad.

De igual modo, también existen determinados factores de localización, en tanto que se detecta una preferencia por los asentamientos turísticos en las franjas costeras meridionales de las Islas, condicionado sobre todo por:

1. Una mejor climatología, sobre todo una mayor insolación y temperaturas, al igual que menores precipitaciones y una acción eólica también menor.

2. Mayor disponibilidad de playas en esta franja meridional que, conjuntamente con las características climáticas mencionadas, favorecen la potenciación del turismo de sol y playas.

3. Una topografía más llana en las citadas franjas meridionales de las Islas, favoreciendo una solución urbanística más viable desde el punto de vista ambiental y de costes, como por ejemplo la urbanización de Maspalomas (al sur de Gran Canaria), o casi todas las que se han terminado construyendo en las franjas costeras de las islas de Lanzarote y Fuerteventura.

En suma, estas circunstancias conllevaron un incremento espectacular del turismo en Canarias, de tal modo que algunas islas conocieron un aumento sin precedentes, en especial desde los años sesenta, tal y como se puede apreciar en el cuadro 3.

Hay que destacar que en el cuadro anterior no se considera el turismo nacional y que varía ostensiblemente por islas, significando éste más de la mitad del internacional en las islas más occidentales de La Gomera, La Palma y El Hierro, mientras que en las restantes -con un peso turístico considerablemente mayor-, su impronta es menor del $20 \%$. Como quiera que fuere, el turismo internacional en Canarias se ha multiplicado por 140 en poco más de 50 años, siendo este aumento mayor en las islas que son en la actualidad Reserva Mundial de la Biosfera, si bien parten de cifras significativamente inferiores en relación con las islas de Tenerife y Gran Canaria que, en 2015, recibieron de forma conjunta 7.5 millones de turistas extranjeros, es decir, el $64 \%$ del turismo internacional que llegó a las Islas. Además, Lanzarote y Fuerteventura, reciben casi otro $35 \%$, por lo que las tres islas más 
occidentales solo algo más del $1 \%$ restante. En suma, ello pone de manifiesto las grandes disparidades que existen en cuanto a la llegada de turistas a las Islas, incluso entre las que son Reserva Mundial de la Biosfera en su integridad, pues de estas últimas Lanzarote y Fuerteventura reciben casi 4.2 millones de turistas, mientras que las tres restantes solo 230 mil.

\section{Cuadro 3 \\ EVOLUCIÓN DEL TURISMO EXTRANJERO EN CANARIAS Y EN PARTICULAR EN LAS ISLAS RESERVA MUNDIAL DE LA BIOSFERA (1960-2015)}

\begin{tabular}{|c|c|c|c|c|c|c|}
\cline { 3 - 7 } \multicolumn{4}{c|}{} & \multicolumn{5}{c|}{ Islas de Canarias Reserva Mundial de la Biosfera } \\
\hline Años & Canarias & Lanzarote & Fuerteventura & La Palma & La Gomera & El Hierro \\
\hline 1960 & 83.100 & s.d. & s.d. & s.d. & s.d. & s.d. \\
\hline 1970 & 821.000 & 25.235 & 5.425 & s.d. & s.d. & s.d. \\
\hline 1980 & 1.692 .388 & 174.708 & 135.715 & s.d. & s.d. & s.d. \\
\hline 1990 & 4.872 .849 & 763.936 & 380.951 & 40.157 & s.d. & s.d. \\
\hline 2000 & 9.975 .977 & 1.750 .507 & 1.305 .874 & 135.324 & s.d. & s.d. \\
\hline 2010 & 8.590 .081 & 1.461 .568 & 1.424 .482 & 103.507 & 87.706 & 2.021 \\
\hline 2015 & 11.759 .849 & 2.193 .273 & 1.965 .573 & 125.953 & 101.067 & 3.655 \\
\hline
\end{tabular}

Fuente: Instituto Canario de Estadística. Elaboración propia.

\section{LAS RESERVAS MUNDIALES DE LA BIOSFERA DE CANARIAS}

La figura de la Reserva Mundial de la Biosfera es un instrumento creado por la UNESCO a comienzos de los años setenta, con la finalidad de proteger la biodiversidad de los ecosistemas especialmente valiosos, donde además prima un compromiso de conservación y de impulsar estrategias y políticas para su población en el marco del desarrollo sostenible. Se pretende con ello un reconocimiento internacional del valor de los espacios declarados como tal, aunque específicamente no es una figura de protección de los espacios naturales (Gesplan, 2013), si bien en la práctica existen otras figuras de protección que se superponen -y complementan- a aquélla bajo diversas fórmulas (Parque Nacional, Parques Naturales, Reservas Naturales, etc.).

En la actualidad existen en el Mundo más de 600 Reservas Mundiales de la Biosfera. Unas 45 de éstas se encuentran en España y, dentro de ellas, siete en Canarias, de las que cinco se corresponden con islas donde la totalidad de su superficie terrestre ha sido declarada como tal. A ello hay que añadirle un espacio marítimo variable que, en algunas islas como es el caso de Fuerteventura y de La Gomera, representan una superficie aún mayor en relación con la terrestre ${ }^{2}$.

2 De igual modo, la UNESCO también ha distinguido varias Reservas Starlight en Canarias. Éstas se corresponden con espacios naturales protegidos donde se establece un compromiso por la defensa de la calidad del cielo nocturno y el acceso a la luz de las estrellas, donde además se establecen las tres zonas de las Reservas de la Biosfera (núcleo, tampón y transición). La justificación de ello viene dada sobre todo por el interés que Canarias tiene para la observación del cielo, pues no en vano, los observatorios astrofísicos más importantes del Hemisferio Norte, además de los de Hawaii, se encuentran en Canarias, en concreto el del Roque de Los Mucha- 
Figura 2

\section{RESERVAS MUNDIALES DE LA BIOSFERA DE LAS CANARIAS ORIENTALES}

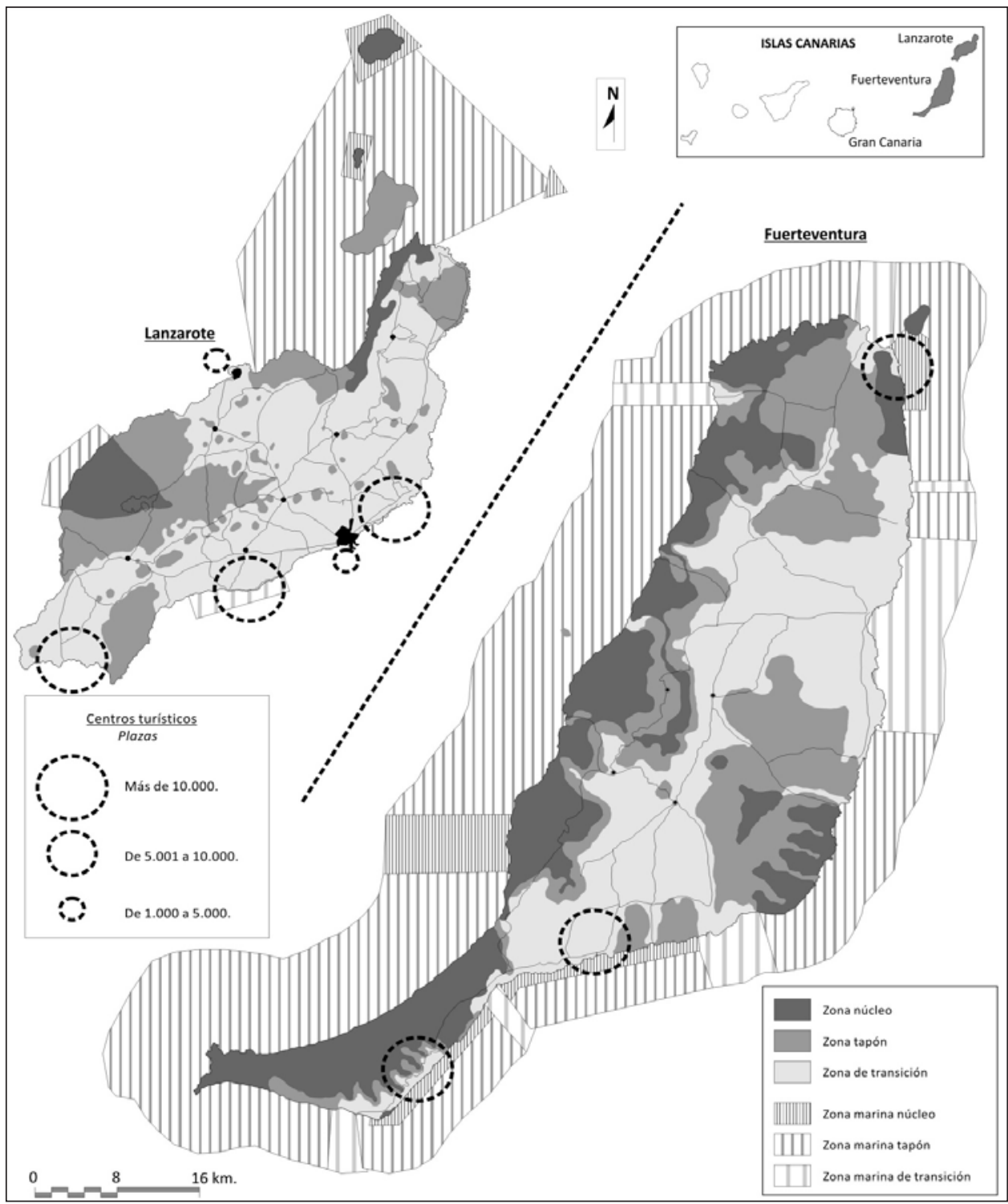

Fuente: GRAFCAN e Instituto Canario de Estadística. Elaboración propia

chos (en La Palma) y el de Izaña (en Tenerife). Así, la isla de La Palma en su integridad obtuvo la citada concesión en el año 2007, siendo la primera Reserva Starlight del Mundo. Las cumbres de Tenerife también obtuvieron la citada membresía en 2013 y Fuerteventura en 2015. 
Figura 3

RESERVAS MUNDIALES DE LA BIOSFERA

DE LAS CANARIAS OCCIDENTALES

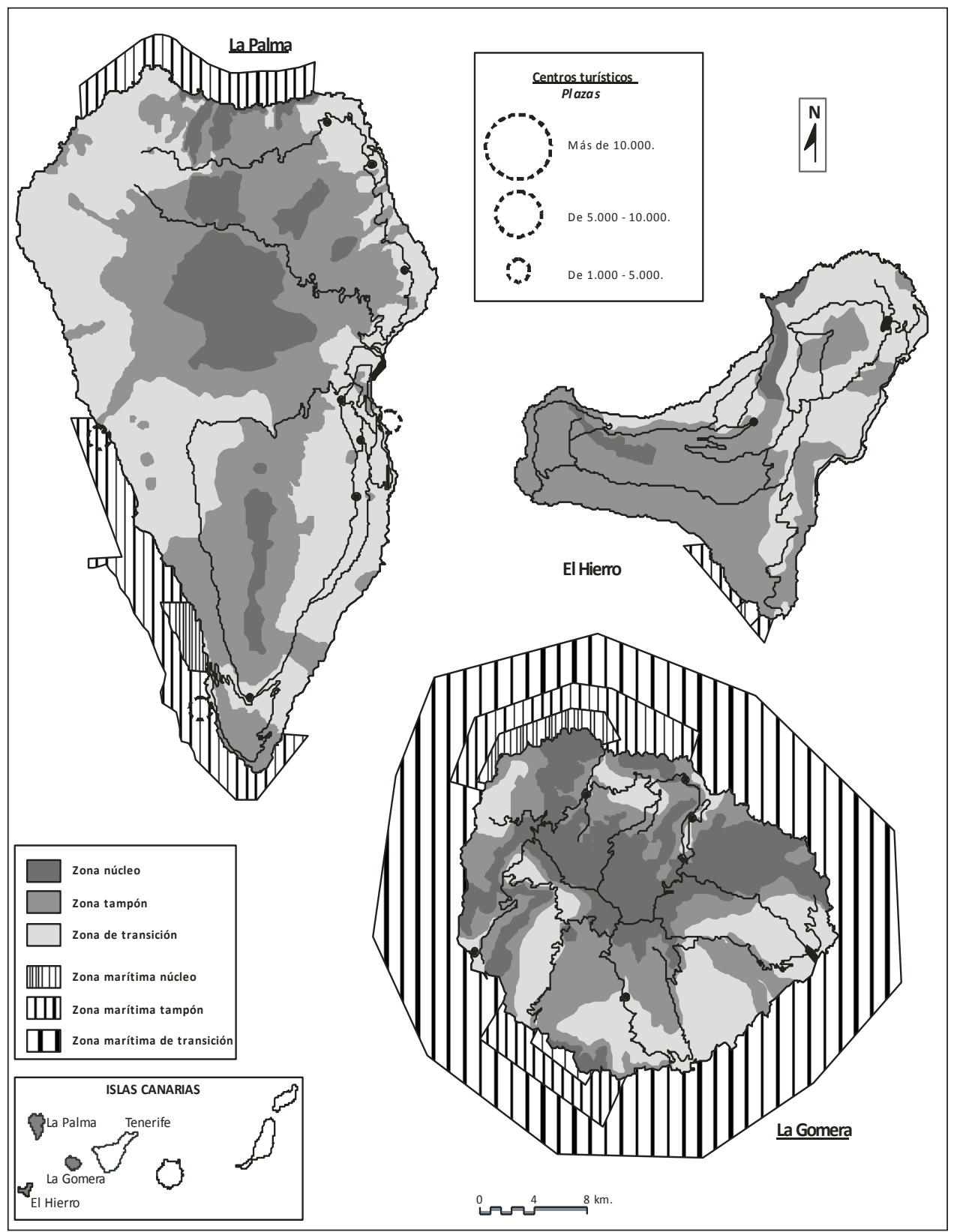

Fuente: GRAFCAN e Instituto Canario de Estadística. Elaboración propia 


\section{Cuadro 4}

\section{RESERVAS MUNDIALES DE LA BIOSFERA DE CANARIAS EN 2016}

\begin{tabular}{|l|c|c|c|c|c|c|c|}
\cline { 5 - 8 } \multicolumn{2}{c|}{} & Reserva & \multicolumn{2}{c|}{ Reserva terrestre (en \%) } & \multicolumn{2}{c|}{ Total terrestre } \\
\cline { 5 - 9 } Islas & \multirow{2}{*}{$\begin{array}{c}\text { marina } \\
\left(\mathbf{k m}^{2}\right)\end{array}$} & Núcleo & Tampón & Transición & $\mathbf{K m}^{2}$ & \% Isla \\
\hline Lanzarote & 1993 & 388,64 & 11 & 36 & 53 & 886,77 & 100.00 \\
\hline El Hierro & 2000 & 90,00 & 4 & 54 & 42 & 268,71 & 100.00 \\
\hline La Palma* & 2002 & 163,66 & 17 & 40 & 43 & 708,32 & 100.00 \\
\hline Fuerteventura & 2009 & $1.878,36$ & 21 & 56 & 23 & $1.659,74$ & 100.00 \\
\hline La Gomera & 2012 & 473,43 & 31 & 36 & 33 & 369,76 & 100.00 \\
\hline Gran Canaria & 2005 & 348,64 & 7 & 33 & 60 & 655,95 & 42.00 \\
\hline Tenerife & 2015 & 332,38 & 12 & 43 & 45 & 154,89 & 8.00 \\
\hline
\end{tabular}

* En 1983 ya se había declarado como Reserva Mundial de la Biosfera una pequeña superficie de esta Isla (El Canal y Los Tiles).

Fuente: UNESCO. Elaboración propia.

Sin duda, las características intrínsecas de Canarias, con una notoria biodiversidad y su rica geomorfología, han coadyuvado a que el $63 \%$ de su territorio haya sido declarado como Reserva Mundial de la Biosfera. Pero lo más interesante es que este territorio recibe al año más de 13 millones de turistas (entre extranjeros y del resto del España), por lo que el análisis del impacto que causa la actividad turística en un territorio tan limitado, se convierte en un asunto de suma importancia para Canarias, sobre todo porque cada una de las islas está "vendiendo" la marca Reserva Mundial de la Biosfera en los distintos mercados turísticos. Así pues, la preservación de esta marca es vital para los destinos turísticos, pues nada sería más contraproducente para un destino que la pérdida de este galardón ${ }^{3}$, sin dejar de pensar también que tan alto reconocimiento desde un organismo internacional como la UNESCO, implica un compromiso de conservación del patrimonio natural y cultural.

\section{INDICADORES DEL IMPACTO DEL TURISMO EN LAS ISLAS RESERVA MUNDIAL DE LA BIOSFERA DE CANARIAS: ¿HACIA UN MODELO DE DESARROLLO SOSTENIBLE?}

El acercamiento a una serie de indicadores de evolución de la población, de llegada de turistas y cómo ello se traduce en consumo energético, de agua, etc., a la vez que determinados rasgos como umbral de pobreza o renta per capita, es el principal objetivo de este apartado, tal y como han desarrollado trabajos anteriores (Hernández Luis, 2006;

3 La concesión de este galardón no es definitivo, sino que se renueva periódicamente en función de determinados parámetros de cumplimiento de la preservación del patrimonio. De este modo, las declaraciones más antiguas de Canarias ya renovaron favorablemente dicha condición (Lanzarote en 2007; El Hierro en 2013; y La Palma en 2014). No obstante, algunas islas, sobre todo las de mayor presión turística como es el caso de Lanzarote y Fuerteventura, corren serio peligro de que en sucesivas revisiones se les pueda retirar esta condición, como ya se ha hecho con una docena de parajes de la Unión Europea. 
Cusick, 2009; Rescia, 2010; Sobral García, 2011). Para ello, establecemos una comparación entre los años 1990 y 2014 en las cinco islas de Canarias Reservas de la Biosfera.

Pues bien, lo primero que detectamos es una ostensible diferencia entre las islas con una mayor presión turística (Lanzarote y Fuerteventura) y el resto, pues en las primeras la población residente ha aumentado en un $120 \%$, al socaire de un incremento de la llegada de turistas del $250 \%$ (2.8 millones de turistas más). Mientras, en las tres islas más occidentales, el aumento poblacional solo fue del $7 \%$ entre ambas fechas, aunque con un incremento del $160 \%$ de los turistas, si bien partían de cifras de llegadas turísticas muy bajas, de tal modo que el incremento turístico solo fue de 130 mil más.

\section{Cuadro 5}

ALGUNOS INDICADORES DEL IMPACTO DEL TURISMO EN LAS ISLAS RESERVA MUNDIAL DE LA BIOSFERA DE LAS CANARIAS ORIENTALES

\begin{tabular}{|l|c|c|c|c|c|}
\cline { 2 - 5 } \multicolumn{1}{c|}{} & \multicolumn{2}{c|}{ Lanzarote } & \multicolumn{2}{c|}{ Fuerteventura } & \multirow{2}{*}{$\begin{array}{c}\text { Variación \% } \\
\text { de las 2 islas }\end{array}$} \\
\hline Parámetros & $\mathbf{1 9 9 0}$ & $\mathbf{2 0 1 4}$ & $\mathbf{1 9 9 0}$ & $\mathbf{2 0 1 4}$ & 118,27 \\
\hline Población & 74.007 & 141.940 & 40.012 & 106.930 & 245,98 \\
\hline Turistas extranjeros & 763.936 & 2.090 .529 & 380.951 & 1.870 .591 & 107,48 \\
\hline Visitas Parque Nacional & 700.000 & 1.452 .365 & --- & --- & 206,19 \\
\hline Consumo energía (Mw/h) & 286.678 & 788.878 & 164.314 & 592.001 & 165,69 \\
\hline Consumo petróleo (Tm) & 151.431 & 402.343 & s.d. & s.d. & 130,02 \\
\hline Consumo agua (m $\left.{ }^{3}\right)$ & 5.627 .317 & 12.943 .938 & s.d. & s.d. & 46,36 \\
\hline $\begin{array}{l}\text { Población bajo umbral de } \\
\text { pobreza (en \%)* }\end{array}$ & 9,40 & 15,60 & 5,70 & 22,10 & 21,14 \\
\hline $\begin{array}{l}\text { Ingreso disponible medio } \\
\text { per capita }(\text { en } € \text { )* }\end{array}$ & 487,88 & 644,29 & 546,51 & 608,72 & \\
\hline
\end{tabular}

* Datos referidos a los años 2001 y 2013.

Fuente: Instituto Canario de Estadística. Elaboración propia.

Todo ello se traduce en impactos diferenciales más o menos significativos, pues el consumo energético ha sido bastante mayor en Lanzarote y Fuerteventura, con aumentos de más del $200 \%$, mientras en las otras tres islas, si bien es importante el incremento, es considerablemente menor. De igual modo, y aunque solo se dispone de los consumos de petróleo y de agua para la isla de Lanzarote, es destacable que éstos estén muy por encima del crecimiento demográfico y, por consiguiente, poniendo en entredicho el valor ambiental de estos espacios Reservas de la Biosfera.

Por su parte, habría que destacar también que, en líneas generales, la población bajo el umbral de la pobreza es considerablemente mayor en las islas de menor presión turística, aunque en estos años -y desde el punto de vista porcentual-, haya aumentado más en las islas orientales. Ello está también en consonancia con los ingresos per capita, por lo que el dilema entre desarrollo turístico - afección medioambiental y el derecho a una mínima calidad de vida, se identifica en estas islas en un debate entre desarrollo y preservación del medio. 


\section{Cuadro 6 \\ ALGUNOS INDICADORES DEL IMPACTO DEL TURISMO EN LAS ISLAS RESERVA MUNDIAL DE LA BIOSFERA DE LAS CANARIAS OCCIDENTALES}

\begin{tabular}{|l|c|c|c|c|c|c|c|}
\hline & \multicolumn{2}{|c|}{ La Palma } & \multicolumn{2}{c|}{ La Gomera } & \multicolumn{2}{c|}{ El Hierro } & \multirow{2}{*}{$\begin{array}{c}\text { Variación \% } \\
\text { de las 3 islas }\end{array}$} \\
\hline Parámetros & $\mathbf{1 9 9 0}$ & $\mathbf{2 0 1 4}$ & $\mathbf{1 9 9 0}$ & $\mathbf{2 0 1 4}$ & $\mathbf{1 9 9 0}$ & $\mathbf{2 0 1 4}$ & 7,02 \\
\hline Población & 82.131 & 83.456 & 17.485 & 20.721 & 7.705 & 10.675 & 760,81 \\
\hline Turistas extranjeros & 40.157 & 106.169 & 37.550 & 98.356 & 1.962 & 3.258 & 160 \\
\hline Visitas Parque Nacional & 120.000 & 375.180 & 150.000 & 817.220 & --- & --- & 341,63 \\
\hline Consumo energía (Mwh) & 108.681 & 225.879 & 22.512 & 61.460 & 11.237 & 39.913 & 129,76 \\
\hline $\begin{array}{l}\text { Población bajo umbral de } \\
\text { pobreza (en \%)* }\end{array}$ & 25,80 & 18,50 & 16,90 & 24,80 & 21,50 & 25,40 & 7,01 \\
\hline $\begin{array}{l}\text { Ingreso disponible medio } \\
\text { per capita (en €)* }\end{array}$ & 369,78 & 607,73 & 440,72 & 596,85 & 397,00 & 521,62 & 42,96 \\
\hline
\end{tabular}

* Datos referidos a los años 2001 y 2013.

Fuente: Instituto Canario de Estadística. Elaboración propia.

\section{PLANIFICACIÓN TURÍSTICA SOSTENIBLE EN LAS ISLAS RESERVA MUNDIAL DE LA BIOSFERA DE CANARIAS}

A continuación hacemos referencia a la planificación y a distintas iniciativas que han marcado el intento por conseguir un modelo de desarrollo sostenible del territorio en las diferentes islas, partiendo de la base de la máxima figura de protección que significa la Reserva Mundial de la Biosfera en cada uno de esos conjuntos insulares.

\subsection{Las recientes normativas en aras de la consecución de un turismo más sostenible en Canarias (2000-2015)}

El marco legislativo canario ha ido evolucionando desde postulados iniciales que, a mediados de los años setenta, se centraban únicamente en una regulación sectorial, hasta el desarrollo de normas que, con el inicio del Siglo XXI, tienen una mayor componente territorial y medioambiental (García Márquez, 2007; González y Ramón, 2013). De cualquier manera, algunos autores consideran que la normativa proteccionista de espacios naturales ha estado, al menos en parte, condicionada y motivada por los desarrollos urbanísticos, entre los que se contarían los turísticos (Martín, 1995; Cáceres, 2002; Fajardo Spínola, 2004).

Pues bien, a comienzos del Siglo XXI, el Gobierno de Canarias formuló las Directrices de Ordenación General y del Turismo de Canarias ${ }^{4}$, que estaban orientadas a promover un turismo más sostenible, todo ello en un contexto de fuerte desarrollo urbanístico asociado al turismo, con la particularidad de que, en aquella época, los derechos sobre licencias de construcción en el futuro, superaban varios cientos de miles de plazas en toda Canarias.

4 Decreto 4/2001, aprobado el 14 de abril de 2003 (Ley 19/2003). 
En esta coyuntura, la filosofía de esta norma era la de congelar los desarrollos turísticos y apostar por la renovación, potenciando desde las políticas públicas la construcción de alojamientos de calidad (preferentemente hoteles de cuatro y cinco estrellas) y vinculados al establecimiento de una oferta complementaria: campos de golf, puertos deportivos, parques temáticos, etc. ${ }^{5}$

Esta normativa, de carácter regional, hizo distinciones insulares que afectaban a tres islas Reserva Mundial de la Biosfera en su integridad: La Palma, La Gomera y El Hierro, donde los desarrollos turísticos habían sido menos importantes. En esta legislación, el modelo turístico para estos tres conjuntos insulares estaba en consonancia con su condición de mayor ruralidad en comparación con los restantes espacios insulares, abogando por un desarrollo sostenible cuyas directrices y líneas estratégicas se definían en la Ley $6 / 2002^{6}$.

Pero también el modelo de polos turísticos urbanos de altas densidades de ocupación, como los de Gran Canaria, Tenerife, Lanzarote y Fuerteventura, han comenzado a regirse desde 1995 (Ley 7/95), al socaire de normas más restrictivas que tenían como objetivo establecer estrategias más sostenibles. Para ello, la normativa turística de más reciente aprobación, otorga a los Planes Insulares de Ordenación (PIO) y, desde la Ley 19/2003, también a los Planes Territoriales Especiales de Ordenación Turística Insular (PTEOTI), la potestad de definir el modelo territorial turístico. Asimismo, las Directrices, facultan a los PTEOTI y, por extensión, a los cabildos insulares como órganos encargados de su redacción, la posibilidad de regular la actividad turística en los respectivos ámbitos insulares.

Estos nuevos instrumentos para la ordenación turística contemplaban aspectos ambientales básicos, establecieron las capacidades de carga de cada zona turística y tenían en cuenta las diferentes figuras de protección, incluidas a título no vinculante las estipulaciones de las Reservas de la Biosfera (Simancas Cruz, 2015), pues no en balde los Consejos de éstas están participados por los mismos Cabildos encargados de la redacción de los PTEOTI, siendo también el presidente de las respectivas corporaciones insulares quien a su vez preside los Consejos de las Reservas de la Biosfera.

Por el momento, la última estrategia pública viene definida por las leyes de Medidas urgentes en materia de ordenación territorial para la dinamización sectorial y la ordenación del turismo (Ley 6/2009), además de la Ley 2/2013 de Renovación y modernización turística de Canarias. Son normas continuistas en cuanto al camino legislativo emprendido a comienzos de Siglo y tienen en los Planes de modernización, mejora e incremento de la competitividad del sector turístico (PMM), el último instrumento estratégico para la ordenación del espacio turístico de Canarias.

5 Cabe destacar también que el crecimiento de las camas de turismo rural no entraban en la citada limitación, si bien ya estaban condicionadas a la utilización de infraestructuras de alojamiento en el medio rural que mantuviesen las características tipológicas o histórico-artísticas del medio rural, así como que hubiesen sido construidas con anterioridad a 1950 y que, en cualquier caso, éstas solo podían ser susceptibles de reforma o ampliación hasta un $25 \%$ de su superficie original, por lo que ya contaban con sus propias "directrices" de crecimiento (Decreto 18/1998, de 5 de marzo, de regulación y ordenación de los establecimientos de alojamiento de turismo rural).

6 Ley 6/2002, de 12 de junio, sobre medidas de ordenación territorial de la actividad turística en las islas de El Hierro, La Gomera y La Palma. 
La recientemente aprobada Ley 9/20157, profundiza en esta misma línea y acaba por consolidar los PMM como los instrumentos de ordenación básicos para continuar el proceso de renovación turística, en un marco estratégico en el que cada vez adquieren más relevancia las diferentes figuras de protección: Espacios Naturales, Zonas de Especial Conservación, Humedales Ramsar, Geosites, y también Patrimonios de la Humanidad y Reservas Mundiales de la Biosfera.

De cara al futuro más inmediato, el Gobierno de Canarias está tramitando un ambicioso Anteproyecto de Ley del Suelo que debería aprobarse en fechas próximas y que está previsto que marque las nuevas directrices en cuanto a legislación sobre los espacios protegidos $^{8}$. Asimismo, también está previsto que a lo largo de 2017 se formule una nueva legislación turística, cuyos principios reguladores nos son aún desconocidos y respecto a los cuales habrá que estar atentos para comprobar si continúa la tendencia inmovilista marcada por la moratoria o si, por el contrario, y tal y como apuntan desde el círculo de empresarios turísticos y respaldada por el Informe sobre competitividad turística el Centro Atlántico de Pensamiento Estratégico (CATPE) ${ }^{9}$, debería abandonarse la línea conservacionista y abogar por un crecimiento que dicho informe califica de "sostenible".

Pero todo hace prever que se mantendrá la dialéctica entre los agentes implicados en la producción del espacio turístico. De una parte, los empresarios, que defienden la liberalización del suelo y la expansión del espacio urbano destinado al turismo; y de otra, los agentes sociales, muchos de los cuales propugnan un control del crecimiento y, por tanto, abogan por limitar el consumo de suelo. Falta por ver de qué lado se posicionará la estrategia legislativa del Gobierno, si de los primeros y retroceder de tal modo que permita una nueva fase desarrollista, o bien mantener la estrategia actual, consistente en ir sustituyendo paulatinamente los establecimientos e infraestructuras de servicio más obsoletas por otras nuevas, pero sin consumir nuevo territorio anejo a los enclaves turísticos ya existentes o, incluso, la potenciación de nuevos núcleos de ocio.

\section{EL CONTROL DEL CRECIMIENTO TURÍSTICO COMO FACTOR DE SOS- TENIBILIDAD DE LAS RESERVAS DE LA BIOSFERA DESDE EL PLANEA- MIENTO TERRITORIAL}

Como particularmente hemos argumentado en el apartado de los indicadores del impacto del turismo en las islas Reserva Mundial de la Biosfera, la actividad turística en Canarias -y en particular en algunas islas del Archipiélago declaradas íntegramente como Reservas Mundiales de la Biosfera como es el caso de Lanzarote y Fuerteventura-, ha supuesto una ostensible modificación de las pautas territoriales, especialmente en el consumo de suelo propiamente turístico, como en el inducido que causa aquél (nuevo suelo

7 Ley 9/2015, de 27 de abril, de modificación de la Ley 2/2013, de 29 de mayo, de Renovación y Modernización Turística de Canarias, y de otras leyes relativas a la ordenación del territorio, urbanismo, medio ambiente, y asimismo de la Ley 4/2014, de 26 de junio, por la que se modifica la regulación del arbitrio sobre importaciones y entregas de mercancías en las Islas Canarias.

8 Aspecto éste que acomete en el Título IV según documento de trabajo del citado Anteproyecto al que hemos tenido acceso.

9 El II Informe CATPE sobre la competitividad turística de Canarias puede consultarse en su web: http:// www.catpe.es/wp-content/uploads/downloads/2016/02/CATPE_Competitividad_Turistica_A42.pdf 
residencial para acoger el incremento demográfico, aumento del consumo energético y de agua, así como una mayor generación de residuos, consumo de territorio para ampliar la red viaria y los aeropuertos, etc. ${ }^{10}$. Por ende, los espacios declarados en Canarias como tales Reservas Mundiales de la Biosfera, presentan un grave problema de perdurabilidad de dicha distinción que, por lo demás, es un reclamo turístico más de la marca "Canarias" en general y de cada isla en particular.

Y es que, la citada modificación de las pautas sostenibles del territorio en Canarias, sobre todo por lo que respecta a la conservación y protección de la biodiversidad, así como de la sostenibilidad del desarrollo económico y humano, está poniendo en serio riesgo la renovación de los citados galardones de la UNESCO, pues en la actualidad nos encontramos en una trascendental etapa de cambio, de repensar el territorio.

En efecto, argumentamos el riesgo de la pérdida de dicha distinción, basándonos en que el informe de gestión que cada diez años las Reservas de la Biosfera se ven obligadas a emitir, deja de tener el carácter casi meramente testimonial que hasta ahora ha tenido. Y es que, en el pasado, este informe preceptivo para renovar la condición de Reserva, no servía más que para, en el peor de los casos, amonestar a quien no cumpliera con los compromisos adquiridos, especialmente en materia de sostenibilidad. En cambio, a partir de 2014, la UNESCO inició el procedimiento conocido como "estrategia de salida", por el que aquella Reserva que no cumpla con las obligaciones estatutarias adquiridas, se le iniciará un "expediente de descatalogación”, pudiendo llegar a perder su condición como Reserva Mundial de la Biosfera ${ }^{11}$. Como ejemplo de algunos de estos casos más llamativos en los últimos diez años y que ponen en grave riesgo la sostenibilidad del territorio al no adecuarse a la legislación vigente, exponemos en el cuadro 7 una selección de estas afecciones medioambientales imputables a actuaciones turísticas en las cinco islas de Canarias declaradas Reservas Mundiales de la Biosfera en su integridad, si bien gran parte de estos casos se concentran en las islas de Lanzarote y Fuerteventura, con mayor desarrollo turístico.

Por tanto -y en aras de evitar el citado expediente de descatalogación de alguna o algunas de las Reservas de la Biosfera del Archipiélago, con el impacto que ello tendría sobre la propia marca turística "Canarias"-, habría que robustecer las estrategias e instrumentos para la conservación de los valores medioambientales y socioeconómicos, interviniendo sobre todo en las herramientas que lleven a la sostenibilidad del desarrollo turístico como actividad básica en su estructura socioeconómica y sus efectos sobre el patrimonio natural y paisajístico. Desde este punto de vista, la Ordenación del Territorio en general y el sistema de instrumentos vinculados a la planificación insular, ha sido una herramienta fundamental. La actualización de su ordenación o la continuidad de la vigencia de estos planes han coincidido con una intensificación del marco legal vinculado al desarrollo sostenible en estos ámbitos definidos como Reserva de la Biosfera.

10 Un buen ejemplo que demuestra la agresión que supone para el medioambiente la construcción en Canarias, especialmente la vinculada con la actividad turística, es que las Islas cuentan en la actualidad con más de 12 mil expedientes abiertos por delitos medioambientales, es decir, más del $40 \%$ de las denuncias ambientales. No obstante, gran parte de las restantes denuncias (por vertidos incontrolados, por afección del paisaje, etc.), guardan una correlación bastante elevada con la actividad turística (Greenpeace, 2014).

11 Resolución 36 C/33. Estrategia del Programa El Hombre y la Biosfera para el período 2015-2025. París, septiembre de 2015. 


\section{Cuadro 7}

PRINCIPALES IRREGULARIDADES URBANÍSTICAS TURÍSTICAS EN LAS CINCO ISLAS DE CANARIAS DECLARADAS RESERVAS DE LA BIOSFERA EN SU INTEGRIDAD Y QUE SE ENCUENTRAN EN LOS TRIBUNALES

\begin{tabular}{|l|l|}
\hline Irregularidades urbanísticas turísticas & Observaciones \\
\hline Teguise (Lanzarote) & $\begin{array}{l}\text { Extinción del Plan Parcial Alborada que preveía la } \\
\text { construcción de 7 mil nuevas camas turísticas. }\end{array}$ \\
\hline Yaiza (Lanzarote) & $\begin{array}{l}\text { El hotel Hesperia de Puerto Calero carece de informe } \\
\text { de compatibilidad con el PIOT }\end{array}$ \\
\hline Yaiza (Lanzarote) & $\begin{array}{l}\text { El hotel Papagayo Arena es ilegal según una sentencia } \\
\text { del Tribunal Superior de Justicia de Canarias }\end{array}$ \\
\hline Teguise y Yaiza (Lanzarote) & $\begin{array}{l}\text { Procesos judiciales contra 27 complejos turísticos por } \\
\text { vulnerar el Plan Insular de 1991 }\end{array}$ \\
\hline El Cotillo (Fuerteventura) & $\begin{array}{l}\text { Anulación de la licencia de 6 hoteles y un campo de } \\
\text { golf dentro del Plan Parcial Costa del Faro SAU-1 sin } \\
\text { autorización previa. }\end{array}$ \\
\hline Corralejo (Fuerteventura) & Hoteles de la cadena RIU en zona de dominio público. \\
\hline San Sebastián de La Gomera (La Gomera) & $\begin{array}{l}\text { Construcción ilegal de un hotel en el Parque Natural } \\
\text { de Majona. }\end{array}$ \\
\hline $\begin{array}{l}\text { El Lamero, El Machal y Las Petroleras (La } \\
\text { Gomera) }\end{array}$ & $\begin{array}{l}\text { Recalificaciones de suelo para su uso turístico y con } \\
\text { carácter irregular }\end{array}$ \\
\hline Tamanca (La Palma) & $\begin{array}{l}\text { Campo de golf y alojamientos turísticos en un paisaje } \\
\text { protegido y LIC. }\end{array}$ \\
\hline Tazacorte (La Palma) & $\begin{array}{l}\text { Caso Los Tarajales, La Nao y El Pozo, afectados por } \\
\text { recalificación residencial y turística irregular }\end{array}$ \\
\hline
\end{tabular}

Fuente: elaboración propia.

En todos los casos, es común el control estratégico del crecimiento turístico a partir de dos tendencias fundamentales:

$\checkmark$ La restricción de nuevos crecimientos e, incluso, la reducción de éstos previstos en versiones del planeamiento insular de los años 70 y 80 en islas con un sistema turístico insular complejo, tales como Lanzarote y Fuerteventura. Incluso, este criterio ha afectado también a las islas centrales de Tenerife y Gran Canaria que, en este caso, no son Reserva de la Biosfera en su integridad.

$\checkmark$ La limitación de los modelos de desarrollo insular hacia un volumen de movimiento turístico limitado o moderado, donde prevalece la intencionalidad del turismo de naturaleza, turismo rural, turismo náutico o aquellos otros muy relacionados con los valores medioambientales.

Esta doble estrategia incluye una variedad de resultados que ejemplifican la diferente orientación del modelo territorial que se ordena en cada Isla, el tratamiento de la heren- 
cia adquirida de planes de décadas precedentes y los derechos inmobiliarios otorgados a la propiedad del suelo o el papel restrictivo de las normativas en los espacios naturales protegidos.

\section{Cuadro 8 \\ PLAZAS TURÍSTICAS APROBADAS EN CANARIAS POR ISLAS SEGÚN EL PLANEAMIENTO INSULAR EN VIGOR (01 DE MARZO DE 2016)}

\begin{tabular}{|c|c|c|c|c|c|c|}
\hline Lanzarote & Fuerteventura & $\begin{array}{c}\text { La } \\
\text { Gomera }\end{array}$ & $\begin{array}{c}\text { La } \\
\text { Palma }\end{array}$ & $\begin{array}{c}\text { El } \\
\text { Hierro }\end{array}$ & $\begin{array}{c}\text { Tenerife y } \\
\text { Gran Canaria }\end{array}$ & $\begin{array}{c}\text { Total de } \\
\text { Canarias }\end{array}$ \\
\hline 82.760 & 236.168 & 4.454 & 25.500 & 2.079 & 328.276 & 682.419 \\
\hline
\end{tabular}

Fuente: Planes Insulares de Ordenación y Planes Territoriales Especiales de Ordenación Turística Insular. Elaboración propia.

Resulta paradigmático el caso de la isla de Lanzarote, cuya prolija experiencia de planificación territorial en las décadas anteriores, ha supuesto que se hayan suprimido nuevos crecimientos de suelos destinados a las urbanizaciones turísticas en un volumen de 250 mil plazas. Pese a ello, las ratios de plazas turísticas por superficie insular o por población residente siguen siendo elevadas; incluso, en mayor medida que las islas con mayor complejidad del sistema territorial y turístico (Gran Canaria y Tenerife) y donde además estas últimas no son Reserva Mundial de la Biosfera en su integridad.

\section{Cuadro 9 \\ RATIO DE PLAZAS TURÍSTICAS ACTUALES Y PLANIFICADAS EN LAS ISLAS RESERVA DE LA BIOSFERA DE CANARIAS EN 2016}

\begin{tabular}{|c|c|c|c|c|c|c|c|c|c|c|}
\hline \multicolumn{1}{|c|}{ Lanzarote } & Fuerteventura & La Gomera & \multicolumn{2}{|c|}{ La Palma } & \multicolumn{2}{c|}{ EI Hierro } \\
\hline \multicolumn{10}{|c|}{ Ratio de plazas / $\mathbf{k m}^{2}$} \\
\hline PS & PP & PS & PP & PS & PP & PS & PP & PS & PP \\
\hline 82,8 & 97,8 & 35,2 & 142,3 & 17,7 & 12,1 & 15,6 & 36,0 & 5,1 & 7,7 \\
\hline \multicolumn{10}{|c|}{ Ratio de plazas / 1.000 habitantes } \\
\hline PS & PP & PS & PP & PS & PP & PS & PP & PS & PP \\
\hline 439,8 & 583,1 & 546,7 & $2.208,6$ & 315,3 & 215,0 & 132,2 & 305,6 & 128,3 & 194,8 \\
\hline
\end{tabular}

PS: Plazas turísticas en servicio; PP: Plazas turísticas planificadas.

Fuente: Planes Insulares de Ordenación y Planes Territoriales Especiales de Ordenación Turística Insular. Elaboración propia.

A diferencia de este esfuerzo, el ejemplo de la isla de Fuerteventura es a nuestro juicio menos afortunado en el control y reducción de la capacidad de crecimiento turístico en relación a su condición de Reserva de la Biosfera, pues las plazas turísticas planificadas en la actualidad se acercan a las 150 por $\mathrm{km}^{2}$ y más de 2.200 por mil habitantes, es decir, cuatro veces más en comparación con las plazas actualmente en servicio (unas 58 mil). En 
este caso, la especial dificultad de las administraciones regional, insulares y locales para llegar a un consenso sobre una planificación insular sostenible, lo consideramos como un factor negativo. Por su parte, en el resto de las Islas -excepto el caso de Lanzarote donde la presión turística también es importante-, se mantienen en parámetros bastante más moderados, quizá acorde con que en las islas occidentales no es factible un turismo de masas asociado al turismo de sol y playa debido a la notoria escasez de playas en relación con las más orientales.

\section{RECOMENDACIONES: HACIA UN MODELO DE DESARROLLO SOSTENI- BLE EN LAS ISLAS RESERVA MUNDIAL DE LA BIOSFERA DE CANARIAS}

Como argumentamos, la concesión del título de Reserva Mundial de la Biosfera exige a los espacios que se les otorga un compromiso con la conservación del medio ambiente y las pautas socioeconómicas originales, en suma, con el desarrollo sostenible, en aras de que las generaciones venideras puedan disfrutar de las excelencias del territorio. Por ello mismo, es vital que la capacidad de carga no supere los límites admisibles. Ya hemos visto que, sobre todo la isla de Fuerteventura, alcanza una ratio de plazas turísticas planificadas que, de construirse en el futuro, comprometerían seriamente la renovación del título de Reserva Mundial de la Biosfera, de ahí que sea primordial un consenso político sobre un techo racional de plazas para estos espacios.

Pero de modo específico, en cada una de las tres zonas en que se divide un espacio Reserva de la Biosfera, se deberían establecer, como mínimo, las siguientes acciones (González, 2015):

En la zona núcleo, en especial, actuaciones encaminadas a la preservación forestal, de limpieza y conservación de los parajes naturales, la recogida selectiva de los residuos, la introducción de energías renovables, el ahorro en el consumo y aprovechamiento de los recursos hídricos, etc. Este tipo de acciones conllevan criterios específicos de sostenibilidad para hacerlos viables y perdurables en el tiempo. Así, cuando se realiza una repoblación forestal ha de hacerse con especies adaptadas al medio ecológico donde se ubican, todo ello adaptado a su franja altitudinal y vertiente. Igualmente, en la zona núcleo es vital la utilización de las energías renovables, dada la alta insolación de muchos parajes, la alta intensidad del viento fruto de los alisios o incluso el aprovechamiento del potencial geotérmico en algunas islas como La Palma y Lanzarote, o también la energía hidroeléctrica como en El Hierro, La Palma y La Gomera.

Por su parte, en la zona tampón o de amortiguación, es recomendable que las intervenciones se orienten a fomentar el empleo local por medio del turismo rural (senderismo, barranquismo, escalada, etc.), o también la producción y venta de productos autóctonos. Todo esto puede ayudar de forma importante a dinamizar la economía local y, con ello, a generar empleo de calidad que contribuya a retener a la población, aunque también es cierto que hace falta mejorar la profesionalización de la mano de obra y en la búsqueda de adecuados canales de comercialización, mejorando el marketing, revalorizando además lo autóctono frente a lo foráneo.

En el exterior, en la zona de transición, además de la acciones anteriores, es el ámbito apropiado para dar a conocer entre la población local las excelencias del patrimonio natural y cultural que atesoran estas reservas. 
Algunas de estas medidas están contempladas en los Planes Insulares de Ordenación (PIO) que tienen estas islas. También muchas de ellas están recogidas en los instrumentos de ordenación de los Espacios Naturales de Canarias que se encuentran dentro de estas zonas Reservas de la Biosfera. En estos planes hay acciones encaminadas a la conservación, al desarrollo económico e investigación, tales como la repoblación forestal, la limpieza de barrancos, la eliminación de vertidos incontrolados, etc. En definitiva, propuestas muy similares a las planteadas por las propias Reservas, lo que significa duplicar de forma innecesaria esfuerzos y medios económicos.

Asimismo, hay determinadas acciones que se han promovido con programas europeos que han funcionado en Canarias, como el Leader, Leader II y el Leader plus que también proponen líneas innovadoras y de interés para mejorar la competitividad económica de estas zonas Reservas de la Biosfera, como la entresaca de pinos y la elaboración de ecomuebles, la producción y envasado de yogurt, la búsqueda de sistemas locales de ahorro de agua, etc. (Sobral, 2011).

Por todo ello, se impone una necesaria coordinación en la realización y ejecución de actividades en aras de conseguir una mayor eficacia y reducción de costes. De esta manera y una vez analizada la situación de partida y teniendo en cuenta el compromiso que se ha adquirido de impulsar estrategias de desarrollo sostenible, las medidas que se proponen deben estar enfocadas a mantener las fortalezas de la zona, centradas en el valor natural y paisajístico, en fomentar las oportunidades derivadas del interés creciente por desarrollar y disfrutar de actividades relacionadas con el medio natural y rural. Pero sobre todo en corregir las debilidades y amenazas propiciadas por una estructura demográfica envejecida y donde la pérdida de las actividades tradicionales es importante.

En definitiva, para mejorar la sostenibilidad de estos espacios insulares Reservas de la Biosfera proponemos una serie de actuaciones:

1. Impulsar el empleo rural para así disminuir la emigración, en especial de la población joven. Las principales líneas de actuación serían la restauración paisajística y la repoblación forestal, así como la puesta en valor del patrimonio etnográfico y cultural, la apertura de rutas temáticas, así como la rehabilitación de senderos que permitan conocer las singularidades y peculiaridades del territorio, etc. (González, 2015).

2. Acabar con el abandono de la agricultura tradicional, pues básicamente ésta es la que mantiene el paisaje rural. Es necesario recuperar las tierras de labor, remozar las parcelas y los muros de los bancales, introducir cultivos ecológicos que cada vez adquieren mayor aceptación entre los consumidores, incrementar la presencia de producciones propias como frutales (almendros, higueras, etc.), así como la de los cultivos forrajeros, que a su vez redunden en la mejora de la cabaña ganadera autóctona. Para ello, son necesarias líneas de ayuda, subvenciones y préstamos a bajo interés que ayuden a fomentar esta práctica y a organizar la comercialización a través de cooperativas para reducir los precios finales e incrementar el beneficio del agricultor y del ganadero. Asimismo, convendría aumentar la producción de queso, vinos y mieles, amparándose en los certificados de denominación de origen y que en el caso de Canarias tan alta notoriedad alcanzaron antaño en el exterior. 
3. Los recursos forestales representan un alto valor paisajístico y medioambiental, pero también aportan beneficios naturales para la propia masa arbórea, ya que contribuye a evitar la escorrentía y, por consiguiente, a recargar los acuíferos. De igual manera, el agua es un recurso que sirve de soporte para generar energía como ocurre con el proyecto Gorona del Viento en la Reserva de la Biosfera de El Hierro, siendo todo ello un reclamo turístico de calidad (Radzi, 2009).

4. En materia de urbanismo, habría que hacer hincapié en remozar las viviendas tradicionales, impulsando la arquitectura tradicional, así como potenciar los nuevos usos como el asociado al turismo rural o el agroturismo. Del mismo modo, evitar al máximo los impactos asociados a nuevas infraestructuras como los tendidos eléctricos, telefónicos, así como minimizar la construcción de nuevas carreteras de gran impacto paisajístico, fomentando el transporte público y una movilidad sostenible (Hernández Luis, 2015), cuestiones todas ellas que son aún una asignatura pendiente, sobre todo en las cinco islas Reserva Mundial de la Biosfera de Canarias.

\section{CONCLUSIONES}

Las Islas Canarias han experimentado un desarrollo inusitado en las últimas décadas, al amparo sobre todo de la actividad turística. Ejemplo de ello es el incremento del turismo desde menos de 100 mil efectivos en 1960, a más de 13 millones en 2015, conllevando un aumento de la población residente del $120 \%$, con notables implicaciones (elevado consumo energético y de agua, generación de residuos, consumo de territorio, etc.). Este aumento, además, ha sido porcentualmente más importante en algunas de las islas de Canarias que han recibido el galardón de Reservas Mundiales de la Biosfera en su integridad, como es el caso de Lanzarote y Fuerteventura, donde el crecimiento demográfico también ha alcanzado un $120 \%$, pero en un periodo de tiempo bastante menor, en concreto, en los últimos 25 años.

Es pues, una situación preocupante, en tanto que las Islas están vendiendo la marca "Reserva de la Biosfera" como un atractivo turístico, si bien el crecimiento tan acelerado de diversos indicadores que argumentamos en este trabajo, sitúa en serio riesgo la renovación periódica del mencionado título por parte de la UNESCO, especialmente después de que en 2014 la UNESCO inició el procedimiento conocido como "estrategia de salida", por el que aquella Reserva que no cumpla con las obligaciones adquiridas, se le iniciará un "expediente de descatalogación”.

En efecto, las Reservas de la Biosfera de Canarias, que representan la nada desdeñable cifra del $63 \%$ de su territorio, se caracterizan por la dualidad entre el desarrollo -sobre todo el turístico- y la conservación, lo cual supone una oportunidad, pero también un reto para contribuir a modificar los procesos territoriales adversos, propiciando un desarrollo capaz de conjugar la explotación sostenible de los recursos con la generación de empleo y de bienestar, todo ello sin menoscabo de los valores patrimoniales que son su principal activo.

Gran parte de esos nocivos procesos territoriales se pueden paliar con la normativa y la ordenación del territorio. En ello se han esforzado, sobre todo en los últimos 15 años, los organismos públicos con instrumentos como los Planes Territoriales Especiales de 
Ordenación Turística Insular (PTEOTI), que han supuesto una planificación integral más sostenible. No obstante, en algunas islas, como es el caso de Fuerteventura -aunque también Lanzarote-, el ordenamiento aún dista bastante de los mencionados criterios sostenibles, pues en el caso de la primera, las plazas turísticas proyectadas, suponen en la actualidad más del doble de la población residente. Así pues, mientras en unas islas, sobre todo las más occidentales, se ha avanzado mucho hacia criterios más sostenibles dentro de los parámetros que exigen las Reservas Mundiales de la Biosfera, en otras, las más orientales, aún distan bastante de unos indicadores más sostenibles, incluso para un horizonte temporal cercano como es 2020-2025.

\section{BIBLIOGRAFÍA}

AINZ IBARRONDO, M.J. et Al. (2008): «Gestión de montes en la Reserva de la Biosfera de Urdaibai: una oportunidad perdida», Boletín de la Asociación de Geógrafos Españoles, nº 46, pp. 329-344.

ARAYA, P. (2007): «El impacto del turismo en la conservación de una Reserva de la Biosfera y el desarrollo de su zona de influencia. El caso de la Reserva Torres del Paine», en Hacia una cultura de conservación de la diversidad biológica. Zaragoza, Monografías Tercer Milenio vol. 6, S.E.A., pp. 115-124.

BAINE, M. (2007): «Coastal and marine resource management in the Galapagos Islands and the Archipelago of San Andres: Issues, problems and opportunities», Ocean \& Coastal Management, $\mathrm{n}^{\mathrm{o}}$ 50(3-4), pp. 148-173.

BATTISE, M. (1990): «Development and implementation of the biosphere reserve concept and its applicability to coastal regions», Environmental Conservation, n 17, pp. 111-116.

BYERS, A.C. (2007): «Changing climates, changing lives: strengthening adaptive response capacities to climate change in the Huascarán Biosphere Reserve, Peru, and Sagarmatha (Mt. Everest) National Park, Nepal», Developments in Earth Surface Processes, $\mathrm{n}^{\circ} 10$, pp. 239-250.

CÁCERES MORALES, E. (2002): Génesis y desarrollo del espacio turístico en Canarias (una hipótesis de trabajo). Las Palmas de Gran Canaria, Ed. Universidad de Las Palmas de Gran Canaria.

CATPE (2016): «II Informe CATPE sobre la competitividad turística de Canarias. Propuestas para encauzar el equilibrio económico-social-medioambiental del Archipiélago Canario». Disponible en: http://www.catpe.es/wp-content/uploads/downloads/2016/02/ CATPE_Competitividad_Turistica_A42.pdf

Consultado el 26 de febrero de 2016.

CHETTRI, N. (2010): «Cross-taxon congruence in a trekking corridor of Sikkim Himalayas: Surrogate analysis for conservation planning», Journal for Nature Conservation, $\mathrm{n}^{\mathrm{o}} 18(2)$, pp. 75-88.

CUSICK, J. (2009): «At the Intersection of Resident, Research and Recreation Stakeholder Interests: East Maui, Hawai'i, as a Sustainable Tourism Destination», Island Studies Journal, $\mathrm{n}^{\circ}$ 4(2), pp. 183-202. 
DUFFY, S.B. et Al. (2001): «Simulating land-use decisions in the La Amistad Biosphere Reserve buffer zone in Costa Rica and Panama», Ecological Modelling, n 140(1-2), pp. 9-29.

ELLIS, E.A. y PORTER-BOLLAND, L. (2008): «Is community-based forest management more effective than protected areas?: A comparison of land use/land cover change in two neighboring study areas of the Central Yucatan Peninsula, Mexico», Forest Ecology and Management, $\mathrm{n}^{\circ}$ 256(11), pp. 1971-1983.

ESQUIVEL, O. E. (2010): «Reserva de la Biosfera La Amistad, Costa Rica, Gestión del turismo de alta montaña en el Parque Nacional Chirripó», en Reservas de Biosfera. Su contribución a la provisión de servicios de los ecosistemas. UNESCO, pp. 172-198.

FAJARDO SPÍNOLA, L. (2004): «Aspectos jurídicos del programa de ajuste turístico en Canarias», Revista de Derecho Urbanístico y Medio Ambiente, no 212, pp. 53-94.

GARCÍA MÁRQUEZ, F. (2007): «La nueva generación de Directrices Territoriales y Turísticas y la Sostenibilidad: la experiencia canaria», Estudios turísticos, nº. 172-173, pp. 89-96.

GAVIRIA, M. (1974): España a go-go: turismo charter y neocolonialismo del espacio. Madrid, Ed. Turner.

GESPLAN (2013): Plan Regional de Ordenación de la Acuicultura de Canarias. Las Palmas de Gran Canaria.

GOBIERNO DE CANARIAS (2009): Estudio del impacto económico del turismo sobre la economía y el empleo de las Islas Canarias. Impactur 2008. Las Palmas de Gran Canaria.

GONZÁLEZ MORALES, A. y HERNÁNDEZ LUIS, J.A. (2005): El desarrollo del turismo en Lanzarote. Santa Cruz de Tenerife, Ed. Idea.

GONZÁLEZ MORALES, A. y RAMÓN OJEDA, A. (2013): «Territorio y políticas turísticas en Gran Canaria: la planificación territorial del turismo», en I Foro Internacional de Turismo Maspalomas (inédito).

GONZÁLEZ MORALES, A. et Al. (2015): «Los nuevos usos turísticos de la Reserva de la Biosfera de la isla de La Palma (Canarias)», Boletín de la Asociación de Geógrafos Españoles, $n^{\circ} 70$, pp. 239-257.

GOURMELON, F. et Al. (2013): «Role-playing game developed from a modelling process: A relevant participatory tool for sustainable development? A co-construction experiment in an insular biosphere reserve», Land Use Policy, no 32, pp. 96-107.

GREENPEACE (2014): Destrucción a toda costa, 2014 (inédito).

HERNÁNDEZ LUIS, J.A. et Al. (2006): «Planeamiento territorial, desarrollo urbano turístico y sostenibilidad en Lanzarote», Ciudad y Territorio: Estudios Territoriales, $n^{\circ}$ XXXVIII (148), pp. 295-330.

HERNÁNDEZ LUIS, J.A. (2008): El turismo de masas. Evolución y perspectivas. Madrid, Ed. Síntesis.

HERNÁNDEZ LUIS, J.A. (2015): «Análisis de la accesibilidad en transporte público al Parque Nacional de Garajonay (isla de La Gomera): Propuesta para su corrección», Boletín de la Asociación de Geógrafos Españoles, nº 68, pp. 57-81.

HERNÁNDEZ MARTÍN, R. (2011): «La cuenta satélite del turismo de Canarias. Metodología, resultados y reflexiones», en El turismo en Canarias. Santa Cruz de Tenerife, Fundación FYDE-CajaCanarias, pp. 67-92. 
HUZUI, J.K. et Al. (2012): «Spatial Pattern Analyses of Landscape using Multi-Temporal Data Sources», Procedia Environmental Sciences, n 14, pp. 98-110.

IGLESIAS, G. y CARBALLO, R. (2011): «Wave resource in El Hierro - an island towards energy self-sufficiency», Renewable Energy, n 36(2), pp. 689-698.

KAREZ, C.S. (2012): «Turismo sustentable en Bañados del Este (Uruguay)», Cuaderno Virtual de Turismo, no 12(2), pp. 85-197.

KERBIRIOU, C. et Al. (2008): «The impact of human frequentation on coastal vegetation in a biosphere reserve», Journal of Environmental Management, $\mathrm{n}^{\circ}$ 88(4), pp. 715-728.

KUIJPER, M. (2003): «Marine and coastal environmental awareness building within the context of UNESCO's activities in Asia and the Pacific», Marine Pollution Bulletin, $n^{\circ} 47(1-6)$, pp. 265-272.

LECO BERROCAL, F. et Al. (2015): «Estudio de la demanda del turismo en el Parque Nacional y Reserva de la Biosfera de Monfragüe», Cuadernos de Turismo, $\mathrm{n}^{\circ} 35$, pp. 231-257.

LI, W. (2006): «Community decisionmaking participation in development», Annals of Tourism Research, $\mathrm{n}^{\mathrm{o}}$ 33(1), pp. 132-143.

MARTÍN ESQUIVEL, J. (Coord.) (1995): La Red Canaria de Espacios Naturales Protegidos. Las Palmas de Gran Canaria, Viceconsejería de Medio Ambiente del Gobierno de Canarias.

MONTOYA AYALA, R. et Al. (2004): «Utilización de un SIG para la determinación del impacto ambiental generado por actividades agrícolas, ganaderas e industriales: el caso del Valle Zapotitlán en la Reserva de la Biosfera de Tehuacán Cuicatlán», Boletín de la Asociación de Geógrafos Españoles, n 38, pp. 115-129.

MOW, J. et Al. (2007): «Collaborative planning and management of the San Andres Archipelago>s coastal and marine resources: A short communication on the evolution of the Seaflower marine protected area», Ocean \& Coastal Management, $\mathrm{n}^{\circ}$ 50(3-4), pp. 209-222.

NGANA, J.O. (2003): «Development of an integrated water resources management plan for the Lake Manyara sub-basin, Northern Tanzania», Physics and Chemistry of the Earth, Parts $A / B / C, \mathrm{n}^{\circ} 28(20-27)$, pp. 1033-1038.

OKANO, T. y MATSUDA, H. (2013): «Biocultural diversity of Yakushima Island: Mountains, beaches, and sea», Journal of Marine and Island Cultures, $\mathrm{n}^{\circ} 2(2)$, pp. 69-77.

ORMAETXEA, O. et Al. (2010): «El presente y futuro de un bien común: el paisaje de una Reserva de la Biosfera», Boletín de la Asociación de Geógrafos Españoles, $\mathrm{n}^{\circ} 52$, pp. 101-115.

PRIMACK, R.B. et Al. (Eds.) (1998): Timber, Tourists and Temple. Conservation and Development in the Maya Forest of Belize, Guatemala and Mexico. Washington, Island Press.

RADZI, A. (2009): «100\% renewable champions: international case studies», en $100 \mathrm{Per}$ Cent Renewable: Energy Autonomy in Action, New York, Earthscan, pp. 93-166.

RESCIA, A.J. (2010): «Changes in land uses and management in two Nature Reserves in Spain: Evaluating the social-ecological resilience of cultural landscapes», Landscape and Urban Planning, $\mathrm{n}^{\circ}$ 98(1), pp. 26-35.

RUBIO GIL, A. (2003): Sociología del Turismo, Barcelona, Ed. Ariel. 
SÁNCHEZ, A. et Al. (2013): «Stable nitrogen isotopes in the turtle grass Thalassia testudinum from the Mexican Caribbean: Implications of anthropogenic development», Estuarine, Coastal and Shelf Science, $\mathrm{n}^{\circ} 135$, pp. 86-93.

SANTANA TURÉGANO, M.Á. (2005): «Turismo, empleo y desarrollo», Papers, nº 77 , pp. 79-104.

SIERRA, J. P. et Al. (2013): «Wave energy resource assessment in Lanzarote (Spain)», Renewable Energy, n ${ }^{\circ} 55$, pp. 480-489.

SIMANCAS CRUZ, M. (2006): «Los modelos de uso turístico de las áreas protegidas de Canarias. Una propuesta metodológica», Investigaciones geográficas, n 39, pp. 25-46.

SIMANCAS CRUZ, M. (2015): La moratoria turística de Canarias. La reconversión de un destino maduro desde la Ordenación del Territorio. La Laguna, Servicio de Publicaciones de la Universidad de La Laguna.

SOBRAL GARCÍA, S. et Al. (2011): «La Reserva de la Biosfera de Gran Canaria: la articulación entre la preservación del medio y el desarrollo sostenible», Boletín de la Asociación de Geógrafos Españoles, n ${ }^{\circ}$ 57, pp. 57-78.

VĂIDIANU, M.N. et Al. (2014): «Promoting Arts-based Activities for Local Sustainability: Danube Delta Case Study», Procedia - Social and Behavioral Sciences, ${ }^{\circ} 122$, pp. 105-109.

VEIGAS, M. e IGLESIAS, G. (2014): «Potentials of a hybrid offshore farm for the island of Fuerteventura», Energy Conversion and Management, n ${ }^{\circ} 86$, pp. 300-308.

VIDAL, O. y RENDÓN-SALINAS, E. (2014): «Dynamics and trends of overwintering colonies of the monarch butterfly in Mexico», Biological Conservation, $\mathrm{n}^{\circ} 180, \mathrm{pp}$. 165-175.

WANHILL, S. (2000): «Small and medium tourism enterprises», Annals of Tourism Reseach, $\mathrm{n}^{\circ}$ 27(1), pp. 132-147.

ZUBE, E.H. y BUSCH, M.L. (1990): «Park-people relationships: an international review», Landscape and Urban Planning, $\mathrm{n}^{\circ}$ 19(2), pp. 117-131. 
